\title{
Effect of Vacuum Contact Agitated Drying on Particle Size Distribution of Aspirin Powder and Aspirin Agglomerates
}

\author{
Zainab Ibrahim S. G. Adiya ${ }^{1, *}$ and Bintu Grema Mustafa ${ }^{2}$ \\ ${ }^{1}$ Department of Pure and Applied Chemistry, Usman Danfodiyo University Sokoto, P.M.B. 2346, Sokoto \\ State, Nigeria \\ e-mail: Zainab.adiya@udusok.edu.ng; xeeadiya@yahoo.com \\ ${ }^{2}$ Department of Chemical Engineering, University of Maiduguri, P.M.B 1069, Off Bama Road, Maiduguri, \\ Borno State, Nigeria \\ * Corresponding author
}

\begin{abstract}
Experiments have been carried out to study the effect of agitation on particle size distribution of aspirin powder and aspirin agglomerates during vacuum contact agitated drying. Morphology G3 by Malvern was used to find the size distribution of the materials under investigation before and after the drying process at $0.1,0.5$ and $0.9 \mu \mathrm{m}$. It was found that due to agitation, aspirin powder portrayed from negligible to significant agglomeration dependent on the diameter of the material under investigation. While attrition and agglomeration compete together during the drying process of aspirin agglomerates, with attrition dominating at 0.1 and $0.5 \mu \mathrm{m}$ and agglomeration at $0.9 \mu \mathrm{m}$.
\end{abstract}

\section{Introduction}

One of the mandatory steps involved in the preparation of many pharmaceutical products is the removal of water or solvents [1], also known as drying [2, 3]. The removal of water through drying has many advantages [4] including but not limited to easy handling and storage, lower transportation costs, and improved stability. Dehydration is the common objective shared by most drying techniques even though these techniques are conceptually different and require modification/ adaptation depending on the type and properties of the compound. The process of converting a solution or suspension into a dry

Received: October 18, 2020; Accepted: November 16, 2020

Keywords and phrases: agitation, drying, vacuum, attrition, agglomerates.

Copyright (C) 2021 Zainab Ibrahim S. G. Adiya et al. This is an open access article distributed under the Creative Commons Attribution License, which permits unrestricted use, distribution, and reproduction in any medium, provided the original work is properly cited. 
powder or cake involves the removal of water and this is done through the application of heat during drying, via conduction, convection, and/or radiation to vaporize water or other solvents $[3,5,6]$. Forced air or vacuum may also be applied in addition to the heat to improve the rate of dehydration.

Several factors such as the physical properties of the product, application of the product, type of energy source available, container closure system, and scalability of the equipment determine the choice of drying method to be used. However, in the pharmaceutical industry, the choice of drying method and appropriate dryer is mainly dependent on the characteristics of the material to be dried and the scale of production i.e. small or large scale $[5,7]$. The cost of the raw ingredient may also be the primary driving factor for the selection of the processing method. For high value pharmaceutical products, low yield or product recovery less than $100 \%$ may not be acceptable [5]. Another critical parameter evaluated during the assessment of a novel drying technology is the energy consumption, quality, and shelf-life of the dried product. The different techniques have an impact on the outcome of the product such as introduction of varying stresses, which may compromise stability. The techniques can also produce dry materials having significantly different characteristics including the particle size distribution.

Drying as one of the final stages in the manufacture of pharmaceutical products can lead to the deterioration of the pharmaceutical products by making it especially prone to microbial growth as a result of any organic solvent that has not been removed [8]. Contact drying occurs when the liquid vaporisation is as a result of heat being supplied to the wet material primarily via contact conduction. Contact drying, specifically under vacuum conditions is often used for thermal-sensitive and oxygen-sensitive pharmaceuticals to avoid thermal decomposition. Because of the nature of many active pharmaceutical ingredients (APIs) and excipients; being heat sensitive, rigid temperature control is required to avoid degradation.

In the pharmaceutical industry, the agitated filter dryer (AFD) is regularly used for filtration, washing and drying of crystalline intermediates and APIs. These unit operations when combined into one single equipment (AFD) offers many advantages such as excellent containment since the filtered, wet cake does not need to be transferred to a separate dryer [9]. The agitated filter dryer (AFD) is very popular in the pharmaceutical industry because of its closed design and its ability to operate under vacuum. Drying under lower pressures greatly reduces the solvent vaporization temperature therefore making drying at lower temperatures best for handling 
temperature-sensitive materials [8]. Such processing challenges for thermo- and oxygensensitive APIs containment to minimize the potential for worker exposure afforded by AFD have resulted to the wide-spread acceptance of the AFD by the pharmaceutical industry $[10,11]$.

Drying is quite a complex process with simultaneous heat and mass transfer accompanied with physical and chemical transformations of products. Drying has severe consequences such as over drying and snowballing, agglomeration and attrition. To date, the effect of drying to the final product is not properly understood $[12,13]$. The aim of this study is to investigate the effect of vacuum contact agitated drying on particle size distribution of aspirin powder and aspirin agglomerates. The specific objectives of the research are to; (1) study the drying behaviour of aspirin powder and aspirin agglomerates in laboratory scale agitated filter dryer (AFD) using vacuum contact agitated drying (2) compare and contrast the drying behaviour of aspirin powder and aspirin agglomerates with respect to drying time and drying rate using vacuum contact agitated drying at exactly same operational conditions and (3) to find the effect of vacuum contact agitated drying on particle size distribution of aspirin powder and aspirin agglomerates after drying using morphology G3 by Malvern at exactly same operating conditions.

\section{Materials and Method}

\subsection{Research materials}

Aspirin powder and aspirin agglomerates were used in this study owing to the welldefined morphology of the aspirin crystals. Hence, even a slight change in the size distribution of the crystals after the drying process can be undoubtedly detected with ease and analysed.

\subsection{Sample preparation}

$1 \mathrm{~kg}$ of the dried aspirin powder or aspirin agglomerates and $1 \mathrm{~kg}$ of distilled water are weight and mixed in a beaker to form a homogeneously slurry used as feed.

\subsection{Operational procedure of agitated filter dryer (AFD)}

After cleaning all units of experimental rig with cleaned water, then acetone, the slurry (homogeneous mixture of aspirin powder and water or aspirin agglomerates and 
water) is poured into the feed port and then the feed port outlet is closed. Vacuum is generated from the headspace to pressure it up to 1 bar. The outlet valve is open to conduct the filtration process under the driving force of vacuum pressure. The filtrate weigh is recorded automatically from the lab view. Then, the vessel is pressurized up to 2 bars after filtration, this is trailed by moving the three-way valve from filtration position to drying position. Vapor is collected at the downstream using a condenser, with a flask placed at the downstream. The dry product is collected by opening the lid. Same procedure is repeated for each experimental run. In the present study, only the drying process was considered. The drying process takes about 15-16 hours to be completed. Data is obtained automatically from the lab view (programmed and installed by SCAPE, University of Leeds) for analysis of results.

The drying process was conducted at $60^{\circ} \mathrm{C}$ with 28 wt. $\%$ initial moisture and agitation speed of 30 rpmin an agitated filter dryer (AFD)

\subsection{Characterization of materials}

The size distribution of aspirin powder and aspirin agglomerates was analyse using morphology G3 by Malvern. Comprehensive explanation of the operating procedure of the equipment can be found in Adiya and Atiku [13].

\section{Results and Discussion}

Figure 1(a) and (b) are the plots of temperature distribution inside wet cake. Four thermocouples were place at the same height but at different position i.e. at a distance of $2 \mathrm{~mm}$. The first thermocouple measures the heating jacket temperature, the second thermocouple place $2 \mathrm{~mm}$ away from the first, measures the top of the cake temperature, thermocouple number three measures the centre/middle of the cake temperature and the fourth thermocouple measures the bottom of the cake temperature. The first and second thermocouple show similar trend in temperature with about $0.2^{\circ} \mathrm{C}$ difference approximately. Meaning the temperature of the two thermocouples is almost the same. The third and fourth thermocouple also shows same temperature trend with negligible difference too (difference is less than $0.5^{\circ} \mathrm{C}$ ). However, it is worth noting that the temperature of the first and second thermocouple is higher than that of the third and fourth thermocouple with over $15^{\circ} \mathrm{C}$. This basically means that the top of the cake is drier than the middle and bottom of the wet cake. This was expected because as we go beneath the wet cake, released of solvent become more and more difficult since particles are overlapping each other. The negligible differences observe between the temperature of 
the first and second thermocouples and that of the third and fourth thermocouples could be attributed to agitation prompt, because one of the major effects of agitation is that it makes the temperature distribution inside wet cake more homogeneous compared to that of static bed.
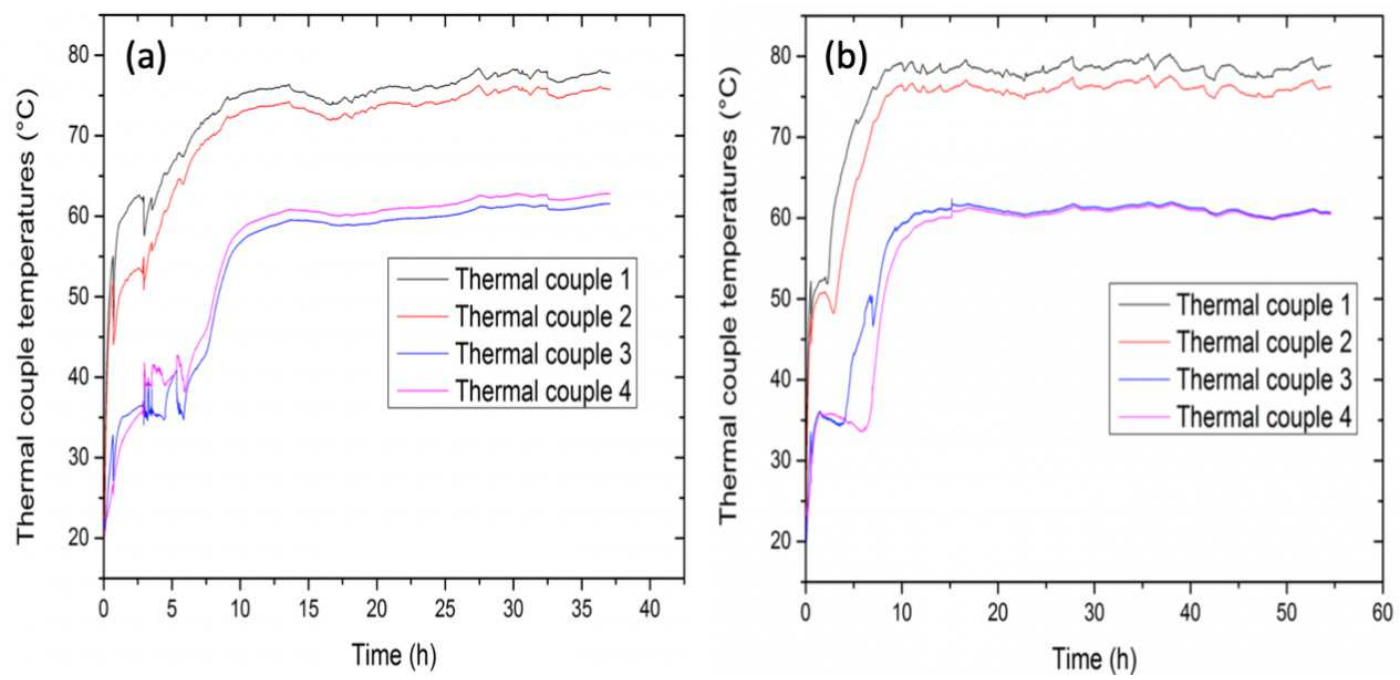

Figure 1. Temperature distribution inside wet cake against time at $60^{\circ} \mathrm{C}$ with $28 \mathrm{wt} . \%$ initial moisture and agitation speed of $30 \mathrm{rpm}$ for; (a) aspirin powder (b) aspirin agglomerates.

The plot of moisture content against time Figure 2(a) shows that the moisture content decreases with drying time for both materials, but the drying time for the materials are not the same. It is reasonable that aspirin powder will have shorter drying time than aspirin agglomerates due to the difference in their pore size and pore volume [14]. The drying rate of aspirin powder is also faster than that of aspirin agglomerates as shown in Figure 2(b), this can also be explained by the materials difference in pore size and pore volume as well as the drying time of the materials under investigation.

Particle size distribution was measured before the drying process and after the drying process using morphologi G3 to find out the effect of agitation on the materials. Attrition (particles breakage to fine powder) and agglomeration (joining of particles together to form cluster) were all observed during the drying process. However, this was dependant on the material under investigation and its diameter i.e. aspirin powder or aspirin agglomerates and $0.1,0.5$ and $0.9 \mu \mathrm{m}$. Attrition is normally caused by shear owing to the rotation of the impeller, while agglomeration is most likely initiated by the liquid 
bridging caused by the capillary forces (due to the presence of a liquid solution in the materials) as reported by Lekhal et al. [15].
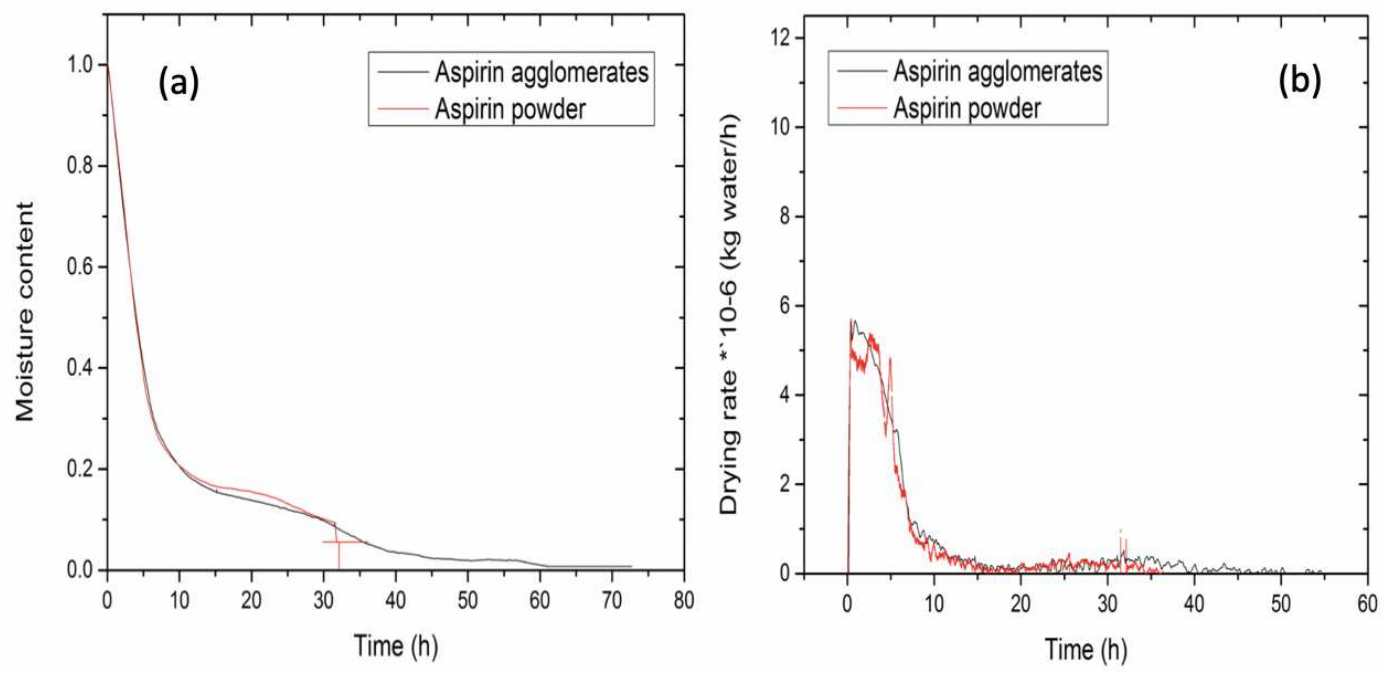

Figure 2. Results of aspirin powder and aspirin agglomerates at $60^{\circ} \mathrm{C}$ with 28 wt. $\%$ initial moisture and agitation speed of $30 \mathrm{rpm}$ (a) Moisture content against time (b) Drying rate against time.

From negligible to significant agglomeration was observed with aspirin powder particles depending on the diameter under investigation. Negligible change in size distribution was observed at diameter of 0.1 and $0.5 \mu \mathrm{m}$ of aspirin powder. Aspirin powder particles at $0.9 \mu \mathrm{m}$ happen to stick to each other in a very large quantity due to agitation, resulting in about twice the initial size distribution of the particles. Thus, forming a cluster together called agglomerates as depicted in Table 1.The initial growth of the agglomerates is from highly saturated aggregates containing a large portion of inter-particle pore space populated by saturated solution. During the drying process, the first step involves the vaporisation of liquid within a group of particles followed by diffusion [16]. As the process continues, the remaining liquid content decreases with those left building liquid bridges, forming agglomerates. If the liquid in the agglomerates contains dissolved substances, then re-crystallization can likely take place resulting in the formation of a layer of crust on the surface of agglomerates. This phenomenon is more likely to take place for low temperature drying conditions especially in vacuum drying.

As shown in Table 1, it was found that the diameter of aspirin agglomerates slightly decreases due to agitation. As the impeller agitate, the frequency of particle-impeller, as 
well as particle-particle collisions increases, and the probability of crystal breakage become high depending on several factors including morphology of the material under investigation. However, this observed phenomenon was seen only in particles with small diameter i.e. 0.1 and $0.5 \mu \mathrm{m}$. Significant agglomeration was observed at $0.9 \mu \mathrm{m}$.

Table 1. Particle size distribution of materials before and after drying with agitation at $60^{\circ} \mathrm{C}$ with $28 \mathrm{wt}$. \% initial moisture and agitation speed of $30 \mathrm{rpm}$.

\begin{tabular}{|c|c|c|c|c|}
\hline \multirow{2}{*}{ Conditions } & \multicolumn{2}{|c|}{ Aspirin powder } & \multicolumn{2}{c|}{ Aspirin agglomerates } \\
\cline { 2 - 5 } & Before Agitation & After Agitation & Before Agitation & After Agitation \\
\hline Diameter $0.1 \mu \mathrm{m}$ & 4.34 & 5.36 & 5.63 & 3.70 \\
Diameter $0.5 \mu \mathrm{m}$ & 12.70 & 12.90 & 13.74 & 12.86 \\
Diameter $0.9 \mu \mathrm{m}$ & 29.13 & 37.58 & 32.13 & 57.74 \\
\hline
\end{tabular}

Direct comparison of present study with previous work is not possible due to differences in material(s) under investigation, drying method used and of less significant is the drying operating conditions. However, Lekhal et al. [17] studied the effects of drying conditions on crystal morphology and found that attrition and agglomeration competed continuously and influenced the crystal morphology at certain moisture contents. Attrition was found to play an important role once the drying rate was very low owing to more particle/particle collisions occurring due to the long duration of drying. With an increase in the drying rate, higher temperature and lower pressure, agglomeration was found to play a role during the drying period. Lekhal et al. [15] dried needle-like crystals and found that the larger crystals were more sensitive to attrition, with most of the attrition occurring during the falling rate drying period. The agglomeration process however was found to dominate with the enlargement of the crystal size and when the Critical Moisture Content (CMC) was exceeded. Those previous studies are in good agreement with the present study.

\section{Conclusions}

The effect of agitation on the drying behaviour of aspirin powder and aspirin agglomerates using vacuum contact drying was predominantly agglomeration and attrition. Agglomeration dominated the drying behaviour of aspirin powder, hence the increase in the size distribution of aspirin powder after drying with agitation. Attrition and agglomeration compete together during the drying process of aspirin agglomerates, 
depending on the diameter of material under investigation i.e. $0.1,0.5$ and $0.9 \mu \mathrm{m}$. Attrition was observed at 0.1 and $0.5 \mu \mathrm{m}$ while agglomeration was seen at $0.9 \mu \mathrm{m}$.

\section{Acknowledgment}

Dr. Tariq Mahmud and Dr. Wei Li are gratefully acknowledged for their guidance and support during this research study.

\section{References}

[1] D. Colucci, J.M. Prats-Montalbán, A. Ferrer and D. Fissore, On-line product quality and process failure monitoring in freeze-drying of pharmaceutical products, Drying Technology (2019) 1-14. https://doi.org/10.1080/07373937.2019.1614949

[2] C. Ratti, Hot air and freeze-drying of high-value foods: a review, Journal of Food Engineering 49(4) (2001), 311-319. https://doi.org/10.1016/S0260-8774(00)00228-4

[3] D. Keith Roper, E.J. Henley and J.D. Seader, Separation Process Principles, John Wiley, Chichester, 2005.

[4] E.K. Sahni, R.H. Bogner and B. Chauhur, Systematic investigation of parameters affecting the performance of an agitated filter-dryer, Journal Pharmaceutical Sciences 102(7) (2012), 2198-2213. https://doi.org/10.1002/jps.23572

[5] R.H. Walters, B. Bhatnagar, S. Tchessalov, K.-I. Izutsu, K. Tsumoto and S. Ohtake, Next generation drying technologies for pharmaceutical applications, Journal of Pharmaceutical Sciences 103(9) (2014), 2673-2695. https://doi.org/10.1002/jps.23998

[6] Z.I.S.G. Adiya and O.D. Azamata. Comparison on the drying efficiency of through circulation convective drying and vacuum contact drying of aspirin powder and aspirin agglomerates, Caliphate Journal of Science and Technology 2 (2020), 132-136.

[7] R.B. Keey, Drying of Loose and Particulate Materials, Hemisphere Publishing, New York, Keith, 1992. https://doi.org/10.1080/07373939208916507

[8] W. Li, Drying of Pharmaceutical Powders Using an Agitated Filter Dryer, University of Leeds, 2014.

[9] D. am Ende, M. Birch, S. J. Brenek and M. T. Maloney, Development and application of laboratory tools to predict particle properties upon scale-up in agitated filter-dryers, $\mathrm{Org}$. Process Res. Dev. 17(10) (2013), 1345-1358. https://doi.org/10.1021/op400080x

[10] E. Sahni, J. Hallisey, B. Morgan, J. Strong and B. Chaudhuri, Quantifying drying performance of a filter dryer: Experiments and simulations, Advance Powder Technology 23(2) (2012), 239-249. https://doi.org/10.1016/j.apt.2011.03.002 
[11] E.K. Sahni and B. Chaudhuri, Numerical simulations of contact drying in agitated filterdryer, Chemical Engineering Science 97 (2013), 34-49. https://doi.org/10.1016/j.ces.2013.04.025

[12] J. Kukura, K. Murray, C. Orella, J. Raffensberger, T. Meher and V. Escalant, Scale up of a granulation phenomenon during the drying of active pharmaceutical ingredients, AICHE 2001 Annual Meeting Reno NV, 2001.

[13] Z.I.S.G. Adiya and F.A. Atiku, Investigation into the drying behaviour of organic solids using a developed model and thermo gravimetric analysis, Nigerian Journal of Solar Energy 30(2) (2019), 93-97.

[14] Z.I.S.G. Adiya and F.A. Atiku, Drying characteristic of aspirin powder and agglomerates using vacuum contact drying, Nigerian Journal of Science 54(1) (2020), 13-19.

[15] A. Lekhal, K.P. Girard, M.A. Brown, S. Kiang, J.G. Khinast and B.J. Glasser, The effect of agitated drying on the morphology of L-threonine (needle-like) crystals, International Journal of Pharmaceutics 270(1-2) (2004), 263-277.

https://doi.org/10.1016/j.ijpharm.2003.10.022

[16] W. Pietsch, Agglomeration in Industry: Occurrence and Applications, Weinheim: WileyVCH, 2004. https://doi.org/10.1002/9783527619795

[17] A. Lekhal, K. P. Girard, M. A. Brown, S. Kiang, B. J. Glasser and J. G. Khinast, Impact of agitated drying on crystal morphology: KCl-water system, Powder Technology 132(23) (2003), 119-130. https://doi.org/10.1016/S0032-5910(03)00056-1 